\title{
Comparison between MRI Findings and Histopathological Diagnosis in the Evaluation of Posterior Fossa Tumors in Pediatric Patients
}

Mahmud $\mathrm{R}^{1}$, Hoque $\mathrm{M}^{2}$, Siddiki $\mathrm{SA}^{3}$, Mahmood $\mathrm{E}^{4}$

Conflict of interest: There was no conflict of interest relevant to this paper to disclose

Funding Agency: Was not funded by any institute or group

Contribution of authors: Mahmud $\mathrm{R}$ was the principal investigator, Hoque $\mathrm{M}$ helped for pro-tocol preparation, Siddiki SA helped in data collection and Mahmood $E$ helped for editorial formatting.

Copyright: @2020bang.BJNS published by BSNS. This article is published under the creative commons CC-BY-NC license. This license permits use distribution (https://creativecommons. orgf/licences/by-nc/4-0/)reproduction in any medium, provided the original work is properly cited and is not used for commercial purposes.

Received: 04.04.19

Accepted: 17.07.19

\begin{abstract}
:
Background: Conventional radiography and CT scan failed to reveal the posterior fossa tumors which not accurately show tumors behind bone. MRI is currently recognized as the optimal screening technique for detection of posterior fossa tumors. We tried to compare the MRI findings with the histopathological findings of different types of posterior fossa tumors in pediatric patients. Histopathological reports were regarded as the gold standard.
\end{abstract}

Objective: To assess the diagnostic effectiveness of MRI in detection of posterior cranial fossa tumors in pediatric patients.

Methods: This cross sectional study was carried out in the department of Neurosurgery, DMCH, NINS and some private hospitals in Dhaka from March, 2012 to November, 2013. Purposive sampling technique was applied and 34 cases were included in the study. Data were collected by specially designed questionnaire and analysed by SPSS.

Results: Out of 34 cases, MRI failed to match with the histopathological diagnosis only in 2 cases. One case was diagnosed as cerebellar astrocytoma by MRI, histopathology proved it brain abscess. In another case, MRI diagnosed as ependymoma but histopathology revealed medulloblastoma.

Conclusion: It can be concluded That MRI is accepted as the most effective imaging modality in the diagnosis of paediatric posterior fossa tumors. T1WI, T2WI, FLAIR, axial, sagittal, coronal and T1WI post contrast sequences permit confident diagnosis and localization of the pediatric posterior fossa tumor.

Key words: Magnetic Resonance Imaging (MRI), Pediatric, Posterior fossa tumor.

Bang. J Neurosurgery 2020; 10(1): 62-66

\section{Introduction:}

During the early period, attempts of posterior fossa tumor surgery failed so frequently that surgeons became reluctant to do the operation in this area. ${ }^{1,2}$ One of the causes behind that was CT failed to reveal the tumors behind bone. MRI ignores bones, provides a clear picture of tumors near and behind bones, produces a wide variety of image angles and soft tissue contrast is much better ${ }^{3}$. Till now histopathological reports are considered as gold standard regarding tumor diagnosis ${ }^{4}$. So we tried to compare the MRI findings with the histopathological findings of different types of posterior fossa tumors in pediatric patients. Our primary aim was to assess the diagnostic effectiveness of MRI in detection of posterior cranial fossa tumors in pediatric patients.

\section{Materials and Methods:}

This cross sectional study was carried out in the Department of Neurosurgery, Dhaka Medical College

1. Dr. Rashed Mahmud, MBBS, MS(Neurosurgery), Assistant Professor, Department of Neurosurgery, Dhaka Medical College Hospital, Dhaka, Bangladesh

2. Dr. Monjurul Hoque, Assistant Professor, Department of Neurosurgery, Rajshahi Medical College Hospital, Rajshahi

3. Dr. Shamiul Alam Siddiki, Assistant Professor, Department of Neurosurgery, Mymensingh Medical College Hospital, Mymensingh

4. Professor Ehsan Mahmood, Ex Professor and Head of the Department of Neurosurgery, Dhaka Medical College Hospital, Dhaka Address of Correspondence: Dr. Rashed Mahmud, Assistant Professor, Department of Neurosurgery, Dhaka Medical College Hospital, Dhaka, email:drrashed2000@gmail.com, cell: 01911091610 
Hospital, National Institute of Neuro Sciences and Hospital (NINS) and some private hospitals in Dhaka from March, 2012 to November, 2013. Clinically suspected and MRI diagnosed cases of posterior fossa tumors in pediatric age group (18 years or less) ${ }^{6}$ were included in the study. 34 cases were selected by Purposive sampling technique.

Results:

Table-I

Age distribution of patients

\begin{tabular}{lc}
\hline Age (Year) & Number $(\mathrm{N}=34)$ \\
\hline $1-5$ & $5(15 \%)$ \\
$6-10$ & $16(47 \%)$ \\
$11-15$ & $8(23 \%)$ \\
$16-20$ & $5(15 \%)$ \\
\hline
\end{tabular}

Most of the patients were in between $6-10$ years $(47 \%)$ followed by $11-15$ years $(23 \%)$.

Table-II

Sex distribution of patients

\begin{tabular}{lc}
\hline Sex & Number $(\mathrm{N}=34)$ \\
\hline Male & $24(71 \%)$ \\
Female & $10(29 \%)$ \\
\hline
\end{tabular}

Males were approximately 2.5 times more than females; M:F:: 24:10 (2.4:1)

Table-III

Distribution of duration of symptoms

\begin{tabular}{lc}
\hline Duration of symptoms (months) & Number $(\mathrm{N}=34)$ \\
\hline $1-3$ & $24(71 \%)$ \\
$4-6$ & $5(15 \%)$ \\
$>6$ & $5(15 \%)$ \\
\hline
\end{tabular}

Most of the patients $(71 \%)$ came to hospital within 3 months of appearance of first symptom, $15 \%$ came in between 3-6 months and 15\% came after 6 months of their first clinical presentation.

Table-IV

Distribution of location of tumors

\begin{tabular}{lc}
\hline Location of tumors & Number $(\mathrm{N}=34)$ \\
\hline Cerebellar hemisphere & $13(38 \%)$ \\
Vermis & $12(35 \%)$ \\
Ventricle & $5(15 \%)$ \\
Pons & $3(12 \%)$ \\
Midbrain & $1(3 \%)$ \\
\hline
\end{tabular}

$38 \%$ tumors were located in cerebellar hemispheres, $35 \%$ were in vermis, $15 \%$ in ventricles, $12 \%$ in pons and $3 \%$ in midbrain.

Table-V

Distribution of state of ventricles

\begin{tabular}{lc}
\hline Ventricles & Number $(\mathrm{N}=34)$ \\
\hline Dilated & $30(88 \%)$ \\
Non dilated & $4(12 \%)$ \\
\hline
\end{tabular}

Most of the patients $(88 \%)$ came to hospital with triventriculomegaly.

Table-VI

Distribution of tumors according to signal intensity

\begin{tabular}{lccccc}
\hline Types of tumor & $\begin{array}{c}\text { Imaging } \\
\text { sequence }\end{array}$ & $\begin{array}{c}\text { Hypo } \\
\text { intense }\end{array}$ & $\begin{array}{c}\text { Hyper } \\
\text { intense }\end{array}$ & $\begin{array}{c}\text { Iso } \\
\text { intense }\end{array}$ & Total \\
\hline Cerebellar & $\mathrm{T} 1 \mathrm{WI}$ & 13 & 0 & 0 & 13 \\
astrocytoma & $\mathrm{T} 2 \mathrm{WI}$ & 0 & 13 & 0 & 13 \\
Medulloblastoma & $\mathrm{T} 1 \mathrm{WI}$ & 6 & 1 & 2 & 9 \\
& $\mathrm{~T} 2 \mathrm{Wl}$ & 0 & 9 & 0 & 9 \\
\multirow{3}{*}{ Brainstem glioma } & $\mathrm{T} 1 \mathrm{WI}$ & 3 & 0 & 1 & 4 \\
& $\mathrm{~T} 2 \mathrm{WI}$ & 0 & 4 & 0 & 4 \\
Ependymoma & $\mathrm{T} 1 \mathrm{Wl}$ & 4 & 2 & 2 & 8 \\
& $\mathrm{~T} 2 \mathrm{Wl}$ & 1 & 7 & 0 & 8 \\
\hline
\end{tabular}

All of the cerebellar astrocytomas were hypointense in T1WI and hyperintense in T2WI. Most of the medulloblastomas, ependymomas and brainstem gliomas were hypointense in $\mathrm{T} 1 \mathrm{WI}$ and hyperintense in T2WI.

Table VII

Distribution of tumors according to contrast enhancement

\begin{tabular}{|c|c|c|c|c|c|}
\hline \multirow[t]{2}{*}{ Types of tumor } & \multicolumn{3}{|c|}{ Contrast of Enhancement } & \multirow[b]{2}{*}{$\begin{array}{l}\text { Hetero- } \\
\text { genous }\end{array}$} & \multirow[b]{2}{*}{ Total } \\
\hline & Mild & Modeate & Strong & & \\
\hline $\begin{array}{l}\text { Cerebellar } \\
\text { astrocytoma }\end{array}$ & 0 & 3 & 9 & 1 & 13 \\
\hline Medulloblastoma & 1 & 1 & 2 & 5 & 09 \\
\hline Ependymoma & 1 & 2 & 1 & 4 & 08 \\
\hline Brainstem glioma & 4 & 0 & 0 & 0 & 4 \\
\hline$\overline{\text { Total }}$ & 6 & 6 & 12 & 10 & 34 \\
\hline
\end{tabular}

Most of the cerebellar astrocytomas enhanced strongly with gadolinium, most of the medulloblastomas and ependymomas were heterogeneously enhancing and all of the brainstem gliomas were mild contrast enhancing. 
Table-VIII

Distribution of tumors by MRI diagnosis

\begin{tabular}{lc}
\hline MRI diagnosis & Number $(\mathrm{N}=34)$ \\
\hline Cerebellar astrocytoma & $13(38 \%)$ \\
Medulloblastoma & $09(26 \%)$ \\
Ependymoma & $08(24 \%)$ \\
Brain stem glioma & $04(12 \%)$ \\
\hline
\end{tabular}

Out of 34 cases of different tumors, MRI diagnosed as cerebellar astrocytoma 13, medulloblastoma 09, ependymoma 08 and brain stem glioma 04.

Table-IX

Distribution of tumors by histopathological diagnosis

\begin{tabular}{lc}
\hline Histopathological diagnosis & Number $(\mathrm{N}=34)$ \\
\hline Cerebellar astrocytoma & $12(35 \%)$ \\
Medulloblastoma & $10(29 \%)$ \\
Ependymoma & $07(21 \%)$ \\
Brain stem glioma & $04(12 \%)$ \\
Brain abscess & $01(3 \%)$ \\
\hline
\end{tabular}

Out of 34 cases of different tumors, histopathology diagnosed as cerebellar astrocytoma 12, medulloblastoma 10, ependymoma 07 and brain stem glioma 04 and brain abscess 01 cases.

Table-X

Misdiagnoses by MRI

\begin{tabular}{lcc}
\hline $\begin{array}{l}\text { No of } \\
\text { misdiagnosed } \\
\text { cases }\end{array}$ & $\begin{array}{c}\text { MRI } \\
\text { diagnosis }\end{array}$ & $\begin{array}{c}\text { Histopathological } \\
\text { diagnosis }\end{array}$ \\
\hline 01 & Cerebellar astrocytoma & Brain abscess \\
01 & Ependymoma & Medulloblastoma \\
\hline
\end{tabular}

Above table shows that MRI failed to accurately diagnose the histopathological variety of posterior fossa tumors in pediatric patients in 2 out of 34 cases.

Table-XI

Comparison between MRI diagnosis and histopathological diagnosis

\begin{tabular}{lcc}
\hline & $\begin{array}{c}\text { MRI } \\
\text { diagnosis }\end{array}$ & $\begin{array}{c}\text { Histopathological } \\
\text { diagnosis } \\
\text { (Gold standard) }\end{array}$ \\
\hline Correct & $32(94 \%){ }_{(P 1)}$ & $34(100 \%)$ \\
Incorrect & $02(6 \%)_{(\mathrm{q} 1)}$ & $00(0 \%)$ \\
Total & $34{ }_{(\mathrm{n} 1)}$ & $34{ }_{(\mathrm{n} 2)}$ \\
\hline
\end{tabular}

$$
Z=\frac{p 1 p 2}{\underline{p 1 q 1 p 2 q}} \text { where... }
$$

$\mathrm{P} 1=$ Proportion of correct diagnosis for $\mathrm{MRI}=94 \%$

$\mathrm{q} 1_{1}=$ Proportion of incorrect diagnosis for MRI=100-p1 = 06\%

$\mathrm{P} 2$ = Proportion of correct diagnosis for Histopathological diagnosis $=100 \%$

$\mathrm{q}_{2}=$ Proportion of incorrect diagnosis for Histopathological diagnosis $=100 " \mathrm{P}_{2}=0 \%$

$Z=1.47$

In $Z$ - distribution table, table $Z$ value at $5 \%$ level is 1.96 . So, $P$ > 0.05. Null hypothesis $\left(H_{0}\right)$ retained.

\section{Discussion}

In our study, the mean age of the patients at presentation was 9.91 years with SD 1.94, the maximum number of patients was between $6-10$ years (47\%, 16 patients) followed by $11-15$ years $(23 \%, 8$ patients). Wilne et al. ${ }^{7}$ have shown a review of 200 cases of brain tumors where mean age at presentation was 7.4 years.

In our series, $71 \%$ (24) patients were male and $29 \%$ (10) were female; male to female ratio was 2.4: 1. Walker and Petronio ${ }^{8}$ found the ratio 1-3: 1. Zakrzewski et al. ${ }^{9}$ found 1.35: 1 and Kadria et al. ${ }^{10}$ found 1.5: 1 .

In this study, majority i.e. $70 \%$ (24) of patients presented to the hospital within 3 months of the appearance of their first symptom. 15\% (5) patients presented within 4-6 months. 15\% (5) patients presented after 6 months. This indicates that posterior fossa tumors cause rapid progression of symptoms, as it causes obstruction to the CSF pathways and develop hydrocephalus earlier. Koellar and Rushing ${ }^{11}$ showed that most (75\%) have had symptoms for less than 3 months.

This study showed that $38 \%$ (13) tumors were located in cerebellar hemisphere, $35 \%$ (12) in vermis, $15 \%(5)$ in ventricles, $12 \%(3)$ in pons and $3 \%(1)$ in midbrain. Likasitwattanakul et al. ${ }^{12}$ found that overall brain tumors were located in the infratentorial region in about $50 \%$ cases. In the infratentorial regions, medulloblastoma and cerebellar astrocytoma were the most common tumors.

The most common tumor of our study was cerebellar astrocytoma 35\%(12), medulloblastoma 29\%(10), ependymoma $21 \%$ (7) and brain stem glioma $12 \%$ (4). Al-Shatoury, Galhom and Engelhard ${ }^{13}$ mentioned that in children, cerebellar astrocytomas comprises about one third, medulloblastomas about one quarter, brainstem gliomas about one quarter \& ependymomas about one eighth. But they differ from Chang et al. ${ }^{14}$ They described the most common tumor found in 
childhood was medulloblastoma (27.5\%) followed by astrocytoma (25.8\%). Our third most common tumor was ependymoma. Spoto et al. ${ }^{15}$ found that ependymomas were the $3^{\text {rd }}$ most common tumors in children after medulloblastoma and astrocytoma and $50 \%$ of ependymomas demonstrate signal heterogenicity which may indicate calcification, necrosis, and tumour vascularity.

Most of our cerebellar astrocytomas strongly enhanced with contrast. Previous studies show that in cerebellar astrocytoma, nodule usually strongly enhance with contrast, cystic wall may or may not enhance ${ }^{16,17}$. Most of the cases of medulloblastomas of our series showed heterogeneous enhancement. Blaster and Harwood-Nash ${ }^{18}$ showed that in medulloblastoma, necrosis, hemorrhage and cavitations are common features, giving these tumors a heterogeneous appearance on MRI. Most of our brain stem gliomas showed mild enhancement and none showed heterogenicity. According to Hesselink and Healy ${ }^{19}$, brain stem gliomas are relatively homogeneous masses without much cystic change, necrosis, vascularity or calcification. Vezina et al. ${ }^{20}$ told that about $50 \%$ of brainstem gliomas will show mild enhancement.

In this series, MRI failed to predict the histopathological variety of tumors in only 2 cases out of 34 cases. Among them one was diagnosed as cerebellar astrocytoma by MRI. That was a welldefined, round, cystic lesion with a solid mural nodule in the right cerebellar hemisphere with minimum edema and intense homogenous enhancement of the solid portion. But it was confirmed as brain abscess by histopathology. Another case was diagnosed as ependymoma by MRI. The mass was fairly large, strong heterogeneously enhancing, having cystic and solid component with mild perilesional edema. It was in the posterior fossa at fourth ventricular region causing marked dilatation of third and both lateral ventricles. It was confirmed as medulloblastoma by histopathology.

To compare between the MRI diagnosis and Histopathological diagnosis, two sample Z proportion test was done. $Z$ value was 1.47. In Z distribution table, $Z$ value at $5 \%$ level is 1.96 . So $P>0.05$ and null hypothesis $(\mathrm{Ho})$ retained. i.e. the difference between MRI diagnosis and Histopathological diagnosis is not significant.

\section{Conclusion:}

It can be concluded that MRI is accepted as the most effective imaging modality in the diagnosis of pediatric posterior fossa tumors. T1WI, T2WI, FLAIR, axial, sagittal, coronal and T1WI post contrast sequences permit confident diagnosis and localization of the pediatric posterior fossa tumor. So if a lesion is suspected in posterior fossa specially in pediatric patients, neither CT nor any other investigation but MRI should be the choice of investigation.

\section{References:}

1. Lee, B.C., Kneeland, J.B., Deck, M.D. and Cahill, P.T., 1984. Posterior fossa lesions: magnetic resonance imaging. Radiology, I53(1), pp.137-143.

2. Cohen-Gadol, A.A. and Spencer, D.D., 2004. Inauguration of pediatric neurosurgery by Harvey W. Cushing: his contributions to the surgery of posterior fossa tumors in children. Historical vignette. Journal of Neurosurgery: Pediatrics, 100(2), pp.225-231.

3. Colosimo, C., Celi, G., Settecasi, C., Tartaglione, T., DiRocco, C. and Marano, P., 1995. Magnetic resonance and computerized tomography of posterior fossa tumors in children: Differential diagnosis and assessment of lesion extent. La Radiologia medica, 90(4), pp.386-395.

4. Aquilina, K., 2013. Posterior fossa tumours in children an overview of diagnosis and management. Advances in Clinical Neuroscience and Rehabilitation, 13(4), pp.2427

6. Khan, M.R. and Rahman, M.K., 2011. Essence of Pediatrics.4th ed. Dhaka: Elsevier. p.63

7. Wilne, S.H., Ferris, R.C., Nathwani, A. and Kennedy, C.R., 2006. The presenting features of brain tumours: a review of 200 cases. Archives of disease in childhood, 91(6), pp.502-506.

8. Walker, M.L. and Petronio, J., 1994. Posterior fossa tumors. In: S.S. Rengachary and R.G. Ellenbogen, eds. 2005. Principles of Neurosurgery. 2nd ed. Detroit: ElsevierMosby. p.533.

9. Zakrzewski, K., Fiks, T., Polis, L. and Liberski, P.P., 2003. Posterior fossa tumours in children and adolescents. A clinicopathological study of 216 cases. Folia Neuropathol, 41(5), pp.251- 252.

10. Kadria, H., Mawlaa, A.A. and Murad, L., 2005. Incidence of childhood brain tumors in Syria (1993-2002). Pediatric Neurosurgery, 41(4), pp.173-177.

11. Koeller, K.K. and Rushing, E.J., 2003. Medulloblastoma: A comprehensive review with radiologic-pathologic correlation. RadioGraphics, 23(6), pp.1613-1637.

12. Likasitwattanakul, S., Katanyuwong, K. and Poneprasert, B., 2003. Brain tumors in children at Mahraj Makorn Chiang Mai Hospital. Chiang Mai Med Bull, 42(4), pp.139-147.

13. Al-Shatoury, H.A.H., Galhom, A.A. and Engelhard, H., 2009. Posterior Fossa Tumors Treatment and Management. eMedicine, [online] 
14. Chang, T., Teng, M.M. and Lirng, J.F., 1993. Posterior cranial fossa tumors in childhood. Neuroradiology, 35(4), pp.274278.

15. Spoto, G.P., Press, G.A., Hesselink, J.R. and Solomon, M., 1990. Intracranial ependymoma and subependymoma: MR manifestations. AJNR Am J Neuroradio, 11(3), pp.83-91.

16. Lacayo, A. and Farmer, P.M., 1991. Brain tumors in children: a review. Annals of Clinical and Laboratory Science, 21(1), pp.26-35.

17. Osborn, A.G. and Rauschning, W., 1994. Brain Tumors and Tumorlike Masses: Classification and Differential
Diagnosis. In: A.G. Osborn, 1994. Diagnostic Neuroradiology. Utah: Elsevier. pp.406-436.

18. Blaster, S.I. and Harwood-Nash, D.C., 1996. Neuroradiology of pediatric posterior fossa medulloblastoma. Journal of neuro-oncology, 29(1), pp.23-34.

19. Hesselink, J.R. and Healy, J.F., 2002. Brainstem and posterior fossa. Neuroweb, [Online] Available at: <http:// spinwarp.ucsd.edu/NeuroWeb/text/br-st.htm>

20. Vezina, L.G. and Packer, J.R., 1994. Infratentorial brain tumors of childhood. Neuroimaging Clinics of North America, 4(2), pp.4 